\title{
Relationship between overall and abdominal obesity and periodontal disease among young adults
}

H. El-Sayed Amin ${ }^{7}$

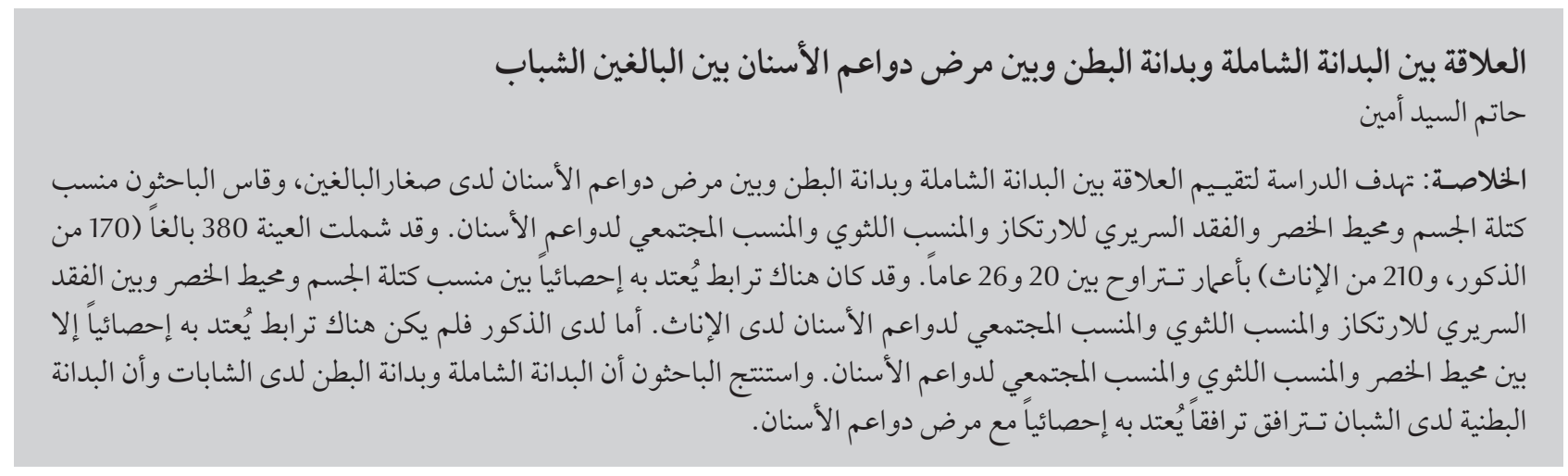

ABSTRACT To assess overall and abdominal obesity and their relation to periodontal disease among young adults, body mass index (BMI) and waist circumference (WC) were measured and clinical attachment loss (CAL), gingival index $(\mathrm{Gl})$ and Community Periodontal Index (CPI) were estimated. The sample comprised 380 adults (170 males and 210 females) aged 20-26 years. There was a significant correlation between both BMI and WC and CAL, GI and CPI in females. In males, a significant correlation was only recorded between WC and GI and $\mathrm{CPI}$. Overall and abdominal obesity in young adult females and abdominal obesity in males were significantly associated with periodontal disease.

\section{Rapport entre obésité générale, obésité abdominale et parodontopathies chez les jeunes adultes}

RÉSUMÉ Afin d'évaluer l'obésité générale, l'obésité abdominale et leur rapport avec les parodontopathies chez les jeunes adultes, l'indice de masse corporelle (IMC) a été calculé, le tour de taille a été mesuré et la perte d'attache, l'indice gingival et l'indice communautaire parodontal (CPI) ont été évalués. L'échantillon comprenait 380 adultes ( 170 hommes et 210 femmes) âgés de 20 à 26 ans. Une étroite corrélation a été établie entre l'IMC, le tour de taille, la perte d'attache, l'indice gingival et le CPI chez les femmes. Chez les hommes, une telle corrélation n'a été constatée qu'entre le tour de taille, l'indice gingival et le CPI. L'obésité générale et abdominale chez les jeunes femmes et l'obésité abdominale chez les hommes étaient associées de manière significative aux parodontopathies. 


\section{Introduction}

Obesity is one of the most significant health risks of modern society, and is now recognized as a major health concern in both developed and developing countries $[1]$. The prevalence of obesity is increasing at alarming rates, approaching epidemic proportions, particularly among children and young adults [2]. Environmental and sociobehavioural influences and metabolic abnormalities are likely the most important risk factors for obesity [3]. Obesity itself has been recognized as a major risk factor for a number of systemic diseases $[4,5,6]$. Therefore, measurement of obesity may provide useful information about the risk of various disease states.

Analysing the effect of nutritional variables on gingival and periodontal health questions the role of obesity and overweightin periodontal disease pathogenesis [7]. The imbalance of the host immune system commonly detected among obese individuals could explain the observed association of obesity with certain diseases including periodontitis [8]. In turn, recent studies have shown that periodontal diseases can exhibit an impact on systemic health such as changing blood chemistry with a rise in inflammatory mediators, affecting blood glucose level and increasing the risk for cardiovascular diseases, suggesting that oral health might affect the health of the entire body $[9,10]$.

Recently, an association between obesity and periodontal disease has been suggested [3]. Furthermore, the results of the Third National Health and Nutrition Examination Survey conducted in the United States of America showed that waist to hip ratio, body mass index (BMI), fat free mass and log sum subcutaneous fat were significantly correlated to periodontitis, signifying that abnormal fat metabolism may be an important factor in the pathogenesis of periodontal diseases [7]. However, studies exploring the relationship between obesity and periodontal disease from developing countries with different eating habits and health behaviours are scarce.

The purpose of the present study was to investigate the relationship between overall and abdominal obesity and periodontal disease among young adults in Egypt.

\section{Methods}

A cross-sectional analytical study was designed to determine whether an association exists between obesity and a variety of periodontal disease measurements among the study sample.

The study sample was consecutively collected from young adults, 20-26 years of age, attending the Physical Medicine and Obesity Clinic, Faculty of Medicine, Tanta University, Egypt during the period 1 July 2007-30 September 2007. Smokers, pregnant women, diabetes patients, and those taking medication for endocrinal disease were excluded from the study to avoid the confounding effect of known risk factors for periodontal disease [11]. Also, those who were not regular brush users or had had periodontal treatment or antibiotic therapy in the 6 months before the beginning of the study were debarred from participation. The final sample was 380 adults (170 males and 210 females) who were willing to participate in the study out of the 620 who were eligible.

\section{Assessment of obesity}

BMI was calculated as an indicator of overall adiposity. Each patient was classified as normal weight (BMI 18.5-24.9 $\mathrm{kg} \backslash \mathrm{m}^{2}$ ), overweight (BMI 25-29.9 kg $\backslash$ $\left.\mathrm{m}^{2}\right)$ or obese $\left(\mathrm{BMI} \geq 30 \mathrm{~kg} \backslash \mathrm{m}^{2}\right)[12]$.

Waist circumference (WC) was used to assess abdominal adiposity; this was divided into 2 categories, normal and high, using the cut-off point $>102$ $\mathrm{cm}$ for males and $>88 \mathrm{~cm}$ for females, based on World Health Organization guidelines [13]. All measurements were taken by well-trained nurses in the Physical Medicine and Obesity Clinic under the supervision of a licensed physician.

The periodontal examinations were performed in the clinic of the Periodontology Department, Faculty of Dentistry, Tanta University under normal clinical conditions with a mouth mirror and periodontal probe. All permanent fully-erupted teeth, excluding third molars, were examined for the following periodontal parameters:

- gingival index (GI) of Loe and Silness: the gingiva was assessed for gingivitis and the individual score was expressed as the mean score of the examined teeth [14];

- periodontal clinical attachment loss (CAL): this was assessed at 6 sites per tooth using the indirect measurement method developed by Ramfjord and only the greatest measurement was recorded [15];

- Community Periodontal Index (CPI): index teeth in each sextant were evaluated and the individual CPI score was defined as the highest score among the examined sextants [16].

All periodontal measurements were carried out by one examiner. Intraexaminer consistency was assessed before the study by examining a group of 20 young adults at the dental clinic of the Periodontology Department twice to achieve uniform interpretation and application of criteria $(\kappa=0.8)$.

Upon enrolment, approval and informed consent was obtained from each participant after explaining the study procedures.

Data were collected, presented and statistically analysed using SPSS, version 13. Means, standard deviations (SDs), Spearman correlation coefficient and chi-squared tests were used as appropriate. The level of significance used was $5 \%$. 


\section{Results}

The mean age of the male and female participants was 23.8 (SD 2.2) years and 22.1 (SD 2.9) years respectively. Males and females had a mean weight of 93.6 (SD 9.8) $\mathrm{kg}$ and 89.4 (SD 12.4) $\mathrm{kg}$ and a mean height of 174.5 (SD 8.7) $\mathrm{cm}$ and 166 (SD 7.2) cm respectively. According to BMI, 26\%, 42\%, 32\% of males and $23 \%, 43 \%$ and $34 \%$ of females respectively were classed as normal, overweight and obese. According to WC measurement, 35\% of males and $19 \%$ of females were classed as normal (Table 1).

Normal, overweight and obese females had a mean attachment loss of 0.2 $\mathrm{mm}, 1.5 \mathrm{~mm}$ and $2.1 \mathrm{~mm}$ respectively, with a statistically significant correlation between CAL and BMI $(r=0.9, P$ $<0.01$ ) (Table 2). Females with normal and high WC had a mean attachment loss of $0.6 \mathrm{~mm}$ and $1.9 \mathrm{~mm}$ respectively; the correlation was statistically significant $(r=0.8, P=0.003)$.

Normal, overweight and obese females had a mean GI of 0.3, 1.0 and 1.8 respectively with a statistically significant correlation between GI and BMI $(r=0.9, P<0.01)($ Table 2$)$.

A mean GI of 0.4 and 0.8 was recorded for males with normal and high WC respectively and the correlation was statistically significant $(r=0.6, P$ $=0.01$ ). Females with normal and high WC had a mean GI of 0.5 and 1.5 respectively, with statistically significant correlation between GI and WC ( $r$ $=0.7, P=0.003$ ).

The association between BMI and CPI scores for females was statistically significant $\left(\chi^{2}=18.9, P<0.01\right)$ (Table $3)$. The proportion of males with normal and high WC who had CPI score of 0-2 was $62.7 \%$ and $39.6 \%$ respectively, whereas $37.3 \%$ of those with normal WC and $60.4 \%$ of those with high WC had a CPI score of 3-4; the difference was statistically significant $\left(\chi^{2}=8.2, P\right.$ $<0.01$ ) (Table 3). Similarly, there was a statistically significant association between WC and CPI scores for females $\left(\chi^{2}=9.5, P<0.01\right)$.

\section{Discussion}

Evidence is rapidly mounting indicating obesityas an independent or aggravating risk factor for several diseases, including coronary heart disease, osteoarthritis and type 2 diabetes mellitus [17]. Studying the relationship between obesity and periodontal disease is, therefore, important since this association could further contribute to increased morbidity of these diseases in overweight or obese individuals [18]. This study was targeted to young adults because the influence of obesity on periodontal disease in older participants might be confounded by the age factor - many older individuals gain some weight as a part of the aging process [19].

The present findings showed a statistically significant positive correlation between obesity in terms of BMI and WC and periodontal measurements of CAL, GI and CPI in female participants. These results were in accordance with previous findings supporting a positive correlation between obesity and periodontal disease among females $[7,20]$. The current study also showed a positive correlation between $\mathrm{WC}$ and periodontal disease as measured by GI and CPI in males, which agreed with Saiti et al. [19,21]. In Saudi Arabia Alabdulkarim et al. found that obesity was significantly associated with alveolar bone loss among adults, with a stronger association in females [22].

Obesity has been postulated to reduce blood flow to the periodontal tissues, promoting the development of periodontal disease [23]. Furthermore, obesity may enhance immunological or inflammatory disorders, which might be the reason obese subjects tend to exhibit escalating poor periodontal status relative to non-obese individuals [24]. A proposed model linking obesity and periodontal infection suggested that insulin resistance mediates the relationship between them. Dietary free fatty acids contribute not only to obesity but also to insulin resistance by enhancing destruction of $\beta$ cells of the pancreas [25]. Insulin resistance, in turn, contributes to a generalized hyperinflammatory state, including periodontal tissue, especially when triggered by oral pathogens [3]. Furthermore, adipocytokines, which include tumour necrosis factor $\alpha$ (TNF- $\alpha$ ) secreted by adipose tissues, appear to be directly related to periodontal destruction [24].

The differences in the results for males and females in this study may be attributed to the fact that overall obesity in males, as measured by BMI, is

\begin{tabular}{|c|c|c|}
\hline \multicolumn{3}{|c|}{ Table 1 Characteristics of the study sample } \\
\hline Characteristic & Males $(n=170)$ & Females $(n=210)$ \\
\hline Mean (SD) age (years) & $23.8(2.2)$ & $22.1(2.9)$ \\
\hline Mean (SD) weight $(\mathrm{kg})$ & $93.6(9.8)$ & $89.4(12.4)$ \\
\hline Mean (SD) height $(\mathrm{cm})$ & $174.5(8.7)$ & $166(7.2)$ \\
\hline \multicolumn{3}{|c|}{ Overall adiposity [No. (\%)] } \\
\hline Normal $^{\text {a }}$ & $44(26)$ & $48(23)$ \\
\hline Overweight ${ }^{b}$ & $71(42)$ & $90(43)$ \\
\hline Obese $^{c}$ & $55(32)$ & $72(34)$ \\
\hline \multicolumn{3}{|c|}{ Abdominal adiposity [No. (\%)] } \\
\hline Normal $^{d}$ & $59(35)$ & $40(19)$ \\
\hline High $^{\mathrm{e}}$ & $111(65)$ & $170(81)$ \\
\hline
\end{tabular}

${ }^{a}$ Body mass index (BMI) $18.5-24.9 \mathrm{~kg} \backslash \mathrm{m}^{2} ;{ }^{b} \mathrm{BMI} 25-29.9 \mathrm{~kg} \backslash \mathrm{m}^{2} ;{ }^{\mathrm{c}} \mathrm{BMI} \geq 30 \mathrm{~kg} \backslash \mathrm{m}^{2} ;{ }^{d} \leq 102 \mathrm{~cm}$ for males and $\leq 88 \mathrm{~cm}$ for females; ${ }^{e}>102 \mathrm{~cm}$ for males and $>88 \mathrm{~cm}$ for females.

$S D=$ standard deviation . 


\begin{tabular}{|c|c|c|c|c|}
\hline \multicolumn{5}{|c|}{$\begin{array}{l}\text { Table } 2 \text { Relationship between gingival index (GI) and periodontal clinical attachment loss (CAL) and overall and abdominal } \\
\text { adiposity in young adults in Tanta, Egypt }\end{array}$} \\
\hline \multirow[t]{2}{*}{ Obesity measurement } & \multicolumn{2}{|c|}{ Mean (SD) GI } & \multicolumn{2}{|c|}{ Mean (SD) CAL } \\
\hline & Females $(n=210)$ & Males $(n=170)$ & Females $(n=210)$ & Males $(n=170)$ \\
\hline \multicolumn{5}{|l|}{ Overall adiposity } \\
\hline Normal $^{a}$ & $0.3(0.1)$ & $0.5(0.1)$ & $0.2(0.1)$ & $0.2(0.1)$ \\
\hline Overweight ${ }^{\mathrm{b}}$ & $1.0(0.2)$ & $0.6(0.2)$ & $1.5(0.2)$ & $0.2(0.1)$ \\
\hline Obese $^{c}$ & $1.8(0.3)$ & $0.7(0.1)$ & $2.1(0.2)$ & $0.3(0.1)$ \\
\hline Spearman correlation coefficient & $r=0.9, P<0.01$ & $r=0.5, P=0.06$ & $r=0.9, P<0.01$ & $r=0.5, P=0.09$ \\
\hline \multicolumn{5}{|l|}{ Abdominal adiposity } \\
\hline Normal $^{d}$ & $0.5(0.3)$ & $0.4(0.2)$ & $0.6(0.7)$ & $0.2(0.1)$ \\
\hline Highe $^{e}$ & $1.5(0.5)$ & $0.8(0.3)$ & $1.9(0.4)$ & $0.3(0.1)$ \\
\hline Spearman correlation coefficient & $r=0.7, P=0.003$ & $r=0.6, P=0.01$ & $r=0.8, P=0.003$ & $r=0.4, P=0.18$ \\
\hline
\end{tabular}

$\mathrm{P}<0.05$ was considered statistically significant.

${ }^{a}$ Body mass index (BMI) $18.5-24.9 \mathrm{~kg} \backslash \mathrm{m}^{2} ;{ }^{b} \mathrm{BMI} 25-29.9 \mathrm{~kg} \backslash \mathrm{m}^{2} ;{ }^{\circ} \mathrm{BMI} \geq 30 \mathrm{~kg} \backslash \mathrm{m}^{2} ;{ }^{d}$ waist circumference $\leq 102 \mathrm{~cm}$ for males and $\leq 88 \mathrm{~cm}$ for females; ${ }^{e}$ waist circumference $>102 \mathrm{~cm}$ for males and $>88 \mathrm{~cm}$ forfemales

$S D=$ standard deviation.

significantly affected by the amount of muscle and weight of bone [20]. Hence, higher BMI scores in males may not necessarily be indicative of obesity [5]. Brochu Starling and Tchernof observed that, within the same BMI category, males with higher WC had a higher risk of having periodontitis [26]. In females, however, BMI may be a more reliable obesity measure [7]. Additionally, topographic distribution of body fat in females might predispose them to periodontal disease [20]. Abdominal and upper body obesity, commonly found in females, is particularly associated with a decrease in the uptake of insulin by the liver with the consequent disturbance of fat metabolism and systemic dyslipidaemia results in enhanced periodontal disease [3]. It has been proposed that the patterns of fat distribution and its relation to periodontal pathogenesis follow those observed with other obesity-related health problems, such as hypertension and type II diabetes, where visceral fat accumulation plays a key role in increasing susceptibility to these diseases [7].
The results of this study raise the question of whether obesity predisposes individuals to periodontal disease, or periodontal disease affects lipid metabolism, or both?

There is some evidence that cytokines such as interleukin-1 $\beta$ (IL-1- $\beta$ ) and interferon $\gamma$ and Gram negative lipopolysaccharides that are produced in high quantities in response to periodontal infection may interfere with lipid metabolism [7]. This may further enhance obesity and obesity-related health problems.

\begin{tabular}{|c|c|c|c|c|c|c|c|c|}
\hline \multirow[t]{4}{*}{ Obesity indicator } & \multicolumn{8}{|c|}{ Community periodontal index } \\
\hline & \multicolumn{4}{|c|}{ Males $(n=170)$} & \multicolumn{4}{|c|}{ Females $(n=210)$} \\
\hline & \multicolumn{2}{|c|}{ 0-2 } & \multicolumn{2}{|c|}{ 3-4 } & \multicolumn{2}{|c|}{ 0-2 } & \multicolumn{2}{|c|}{$3-4$} \\
\hline & No. & $\%$ & No. & $\%$ & No. & $\%$ & No. & $\%$ \\
\hline \multicolumn{9}{|l|}{ Overall adiposity } \\
\hline Normal $^{a}$ & 24 & 54.5 & 20 & 45.5 & 36 & 75.0 & 12 & 25.0 \\
\hline Overweight ${ }^{\mathrm{b}}$ & 33 & 46.5 & 38 & 53.5 & 39 & 43.3 & 51 & 56.7 \\
\hline Obese $^{c}$ & 24 & 43.6 & 31 & 56.4 & 26 & 36.1 & 46 & 63.9 \\
\hline Significance & \multicolumn{4}{|c|}{$\chi^{2} 1.2, P=0.6$} & \multicolumn{4}{|c|}{$\chi^{2} 18.9, P<0.01$} \\
\hline \multicolumn{9}{|c|}{ Abdominal adiposity } \\
\hline Normal $^{\mathrm{d}}$ & 37 & 62.7 & 22 & 37.3 & 28 & 70.0 & 12 & 30.0 \\
\hline Highe & 44 & 39.6 & 67 & 60.4 & 73 & 42.9 & 97 & 57.1 \\
\hline Significance & \multicolumn{4}{|c|}{$\chi^{2} 8.2, P<0.01$} & \multicolumn{4}{|c|}{$\chi^{2} 9.5, P<0.01$} \\
\hline
\end{tabular}

$\mathrm{P}<0.05$ was considered statistically significant.

${ }^{a}$ Body mass index (BMI) $18.5-24.9 \mathrm{~kg} \backslash \mathrm{m}^{2} ;{ }^{b} \mathrm{BMI} 25-29.9 \mathrm{~kg} \backslash \mathrm{m}^{2} ;{ }^{c} \mathrm{BMI} \leq 30 \mathrm{~kg} \backslash \mathrm{m}^{2} ;{ }^{d}$ waist circumference $\leq 102 \mathrm{~cm}$ for males and $\leq 88 \mathrm{~cm}$ for females; ${ }^{e}$ waist circumference $>102 \mathrm{~cm}$ for males and $>88 \mathrm{~cm}$ for females. 
Although in this study a significant correlation was found between obesity and periodontal disease, it is not possible to prove causality. Further prospective studies are needed to address the question of causality and to determine if obesity is a true risk factor for periodontal disease, especially among the younger population. If this proves to be the case, periodontal disease prevention could be included in planned intervention campaigns designed to prevent obesity-related diseases. Conversely, prevention and management of obesity may be an adjunctive approach to improving periodontal health.

\section{Acknowledgment}

The author wishes to thank Dr Hanan M. El-Saadany, Department of Physical Medicine, Faculty of Medicine, Tanta University, for the great help she provided during this study.

\section{References}

1. Doll S, Paccaud F, Bovert B. Body mass index, abdominal adiposity and blood pressure: consistency of their association across developing and developed countries. International journal of obesity and related metabolic disorders, 2002, 26:48-57.

2. Freidmn G. Obesity in the new millennium. Nature, 2000, 404:632-4.

3. Genco RJ et al. A proposed model linking inflammation to obesity, diabetes, and periodontal infections. Journal of periodontology, 2005, 76(11 Suppl.):2075-84.

4. Martí A, Marcos A, Martínez JA. Obesity and immune function relationships. Obesity reviews, 2001, 2:131-40.

5. Wakai $\mathrm{K}$ et al. Associations of medical status and physical fitness and periodontal disease. Journal of clinical periodontology, 1999, 26(10):664-72.

6. Hubert HB, Feinleib M, McNamara PM. Obesity as an independent risk factor for cardiovascular disease: a 26-year follow-up of participants in the Framingham Heart Study. Circulation, 1983, 67:968-77.

7. Wood N, Johnson R, Streckfus F. Comparison of body composition and periodontal disease using nutritional assessment techniques. Journal of clinical periodontology, 2003, 30:321-7.

8. Lamas O, Marti A, Martinez J. Obesity and immunucompetence. European journal of clinical nutrition, 2002, 56(Suppl. 3):842-45.

9. Machado AC, Quirino MR, Nascimento LF. Relation between chronic periodontal disease and plasmatic levels of triglycerides, total cholesterol and fractions. Brazilian oral research, 2005, 19(4):284-9.

10. Genco RJ et al. Overview of risk factors for periodontal disease and implications for diabetes and cardiovascular disease. Compendium of continuing education in dentistry, 2001, 22(2 Spec. No.):21-3.

11. Manabu M, Masazomi H, Yuka K. Relationship between blood triglycerides levels and periodontal status. Community dental health, 2004, 21:32-6.

12. National Institutes of Health. Clinical guidelines on identification, evaluation, and treatment of overweight and obesity in adults-the evidence report. Obesity research, 1998, 6(Suppl.):51S-209S.

13. Obesity: prevention and management of the global epidemic. Report of a WHO consultation on obesity. Geneva, World Health Organization, 1997.
14. Löe $\mathrm{H}$. The gingival index, the plaque index and the retention index system. Journal of periodontology, 1967, 38(6):610-6.

15. Ramfjord SP. Indices for prevalence and incidence of periodontal disease. Journal of periodontology, 1959, 30-51.

16. Basic oral health survey, 4th ed. Geneva, World Health Organization, 1997.

17. Wilson PW et al. Overweight and obesity as determinants of cardiovascular risk: the Framingham experience. Archives of internal medicine, 2002, 162(16):1867-72.

18. Tessari P. Changes in protein, carbohydrate, and fat metabolism with aging: possible role of insulin. Nutrition reviews, 2000, 58:11-9.

19. Saiti T, Shimazaki Y, Sakamoto M. Obesity and periodontitis. New England journal of medicine, 1998, 339:482-3.

20. Dalla Vecchia CF et al. Overweight and obesity as risk indicators for periodontitis in adults. Journal of periodontology, 2005, 76(10):1721-8

21. Saiti T, Shimazaki Y, Koga T. Relationship between upper body obesity and periodontitis. Journal of dental research, 2001, 80:1631-6.

22. Alabdulkarim $M$ et al. Alveolar bone loss in obese subjects. Journal of the International Academy of Periodontology, 2005, $7(2): 34-8$.

23. Shuldiner A, Yang R, Gong D. Resistin, obesity and insulin resistance-the emerging role of the adipocytes as an endocrine organ. New England journal of medicine, 2001, 345:1345-6.

24. Nishida N, Tanaka M, Hayashi N. Determination of smoking and obesity as periodontitis risks using the classification and regression tree method. Journal of periodontology, 2005, 76:923-8.

25. Saiti T, Shimazaki Y, Yamashita Y. Association between periodontitis and exercise capacity. Periodontol insights, 1999, 6:9-12.

26. Brochu M, Starling R, Tchernof A. Visceral adipose tissue is an independent correlate of glucose disposal in older postmenopausal women. Journal of clinical endocrinology and metabolism, 2000, 85:2378-84. 